\title{
O PNBE, A LITERATURA E O ENDEREÇAMENTO ESCOLAR
}

\author{
Rildo Cosson \\ rcosson@gmail.com \\ Aparecida Paiva \\ paiva.aparecida@gmail.com
}

\begin{abstract}
In the judgment-making world we all inhabit, nobody claims or even desires to speak from a plane of perfect, interest- and personality-transcending objectivity; but neither does anybody truly behave as if the inflections of personality or social circumstance made nonsense of all efforts at accuracy of observation or fairness in judgment. Seeing things as they are: literary judgment and disinterestedness - Timothy Peltason
\end{abstract}

Em um ensaio no qual trata da formação do leitor, Regina Zilberman diz que a legitimidade do uso da literatura na sala de aula vem tanto "da relação que estabelece com seu leitor, convertendo-o num ser crítico perante a sua circunstância" quanto "do papel transformador que pode exercer dentro do ensino, trazendo-o para a realidade do estudante" (Zilberman, 2003, p. 30). Esse papel da literatura reivindicado por Zilberman no campo educacional ecoa o conhecido texto de Antonio Candido para quem "a literatura corresponde a uma necessidade universal que deve ser satisfeita sob pena de mutilar a personalidade, porque pelo fato de dar forma aos sentimentos e à visão do mundo ela nos organiza, nos liberta do caos e portanto nos humaniza. Negar a fruição da literatura é mutilar a nossa humanidade" (Candido, 1995, p. 256). Todavia, se o acesso à literatura é um direito do ser humano e a presença da literatura na escola se justifica pela sua participação essencial na formação do leitor, qual literatura é essa? Ou melhor, quais são os textos que podem ser assim rotulados? 
No texto de Candido, a literatura consiste em "todas as criações de toque poético, ficcional ou dramático em todos os níveis de cultura, desde o que chamamos folclore, lenda, chiste, até as formas mais complexas e difíceis da produção escrita das grandes civilizações" (Candido, 1995, p. 3). No texto de Zilberman, literário é aquele texto que possui qualidade estética e valor artístico, ou seja, aquela obra que, recusando cumprir uma missão pedagógica, "aponta a um conhecimento de mundo" e apresenta-se "como o elemento propulsor que levará a escola à ruptura com a educação contraditória e tradicional” (Zilberman, 2003, p. 30). É dentro deste horizonte amplo da literatura como um direito de todos e mais restrito da literatura como parte da formação escolar do leitor que se localiza a seleção de obras literárias no Programa Nacional da Biblioteca da Escola (PNBE).

Parte das políticas públicas de incentivo à leitura, o PNBE é um programa que tem como objetivo a aquisição de obras literárias para compor o acervo das bibliotecas escolares do sistema público de ensino. Lançado em 1997, o PNBE faz parte de uma trajetória que reúne outras ações do governo federal na área da leitura, tais como o Programa Nacional Salas de Leitura, instituído em 1984 e transformado em Programa Nacional Salas de Leitura/Bibliotecas Escolares em 1988; o Programa Nacional de Incentivo à Leitura (Proler), criado pela Biblioteca Nacional em 1992; e o Pró-Leitura, também iniciado em 1992, numa iniciativa conjunta do MEC, Secretarias de Educação dos Estados, Universidades e o governo francês; e o Programa Nacional Biblioteca do Professor, que funcionou de 1994 a 1997, sendo substituído pelo PNBE (Berenblum e Paiva, 2006; Brasil, 2009; UFMG, 2012a).

Inicialmente, no período de 1988 a 2000, o PNBE adquiriu os livros para as bibliotecas das escolas. Em 1998, foi distribuído para as escolas do segundo ciclo do ensino fundamental um acervo de 123 títulos composto por obras literárias, dicionários, globos terrestres, atlas histórico e um guia para orientar o uso do acervo. Em 1999, o acervo foi constituído com obras de literatura infanto-juvenil e foi distribuído para todas as escolas dos anos iniciais do ensino fundamental com mais de 150 alunos matriculados. Em 2000, o acervo foi constituído apenas com textos elaborados pelo MEC ou sob sua demanda para uso dos professores e distribuído para mais de 18 mil escolas do ensino fundamental. Nos anos de 2001 a 2003, o MEC direcionou os acervos para o uso pessoal e privado dos alunos, criando as coleções Literatura em Minha Casa, primeiramente dirigidas para alunos de $4^{\mathrm{a}}$ e $5^{\mathrm{a}}$ séries do ensino fundamental (2001) e posteriormente apenas $4^{\mathrm{a}}$ série (2002), depois para alunos de $4^{\underline{a}}$ e $8^{\underline{a}}$ série, juntamente com a coleção Palavra da Gente, para alunos da Educação de Jovens e Adultos (2003). 
Neste último ano, além dos livros das coleções Literatura em Minha Casa e Palavra da Gente, também foram constituídos acervos para a Casa da Leitura (bibliotecas itinerantes para uso comunitário no município), a Biblioteca Escolar e a Biblioteca do Professor. Em 2004, o Programa suspendeu suas ações para reavaliação e retornou em 2005 com a aquisição e distribuição de livros apenas para a biblioteca escolar e com foco na literatura. A partir daí o PNBE passou a alternar a seleção das obras entre as escolas dos anos iniciais do ensino fundamental e as dos anos finais, progressivamente incorporando outros segmentos educacionais, como a educação infantil no PNBE/2008, ensino médio no PNBE/2009 e educação de jovens e adultos no PNBE/2010. Além disso, passou a constituir PNBEs para outros tipos de textos e públicos específicos, a exemplo do PNBE - Educação Especial- 2008, o PNBE do Professor - 2010, o PNBE dos Periódicos - 2012 e o PNBE - Temático - 2012 (Brasil, 2012; Silva, 2009; Paiva et al, 2008).

A aquisição de obras para atender a todas essas frentes tornou o PNBE um programa complexo, tanto do ponto de vista da seleção quanto da compra dos livros, sobretudo porque envolve quantidades e valores vultosos. $\mathrm{Na}$ edição do PNBE 2012 - Literatura, por exemplo, foram adquiridas 10.485.353 obras impressas, 743.061 obras em MecDaisy' ao custo de R\$60.807.712, 32. Esses livros foram distribuídos para 86.088 escolas de educação infantil, atendendo 3.581.787 alunos; 115.344 escolas de Ensino Fundamental ( $1^{\circ}$ ao $5^{\circ}$ ano), correspondendo a 14.565.893 alunos; e 38.769 escolas de Educação de Jovens e Adultos, com 4.157.721 alunos. Na edição de 2013 - Literatura, está prevista a distribuição de aproximadamente 6,7 milhões de obras literárias a mais de 50 mil escolas do ensino fundamental e 18,8 mil do ensino médio, com valores que alcançam a soma $\mathrm{R} \$ 66$ milhões (Brasil, 2012).

Por conta desses números, não há dúvidas de que o PNBE causa forte impacto no mercado editorial brasileiro. Impacto que acaba atingindo a própria literatura e o seu uso na escola, como bem adverte Marisa Lajolo em relação à literatura infantil. Para a autora, "o necessário rigor da seleção operada, pautada por critérios rígidos preestabelecidos, atenta a minúcias, corre o risco tanto de pasteurizar o gênero quanto de torná-lo uma espécie de refém de expectativas talvez alheias à literatura" (Lajolo, 2010, p. 107-8). Esses e outros riscos que um processo da magnitude do PNBE necessariamente envolve não podem ser avaliados, quiçá verdadeiramente compreendidos, sem que se conheçam as etapas e os critérios usados para a seleção das obras. É por essa razão que este estudo tem como objetivo

${ }^{1}$ MecDaisy é um software desenvolvido pelo MEC em parceria com a Universidade Federal do Rio de Janeiro (UFRJ) que possibilita transformar arquivos de texto em arquivos de áudio, assim como gerar documentos para impressão de textos em braile. 
analisar contextualmente as três etapas do processo e os critérios de ordem pedagógica, literária e estatal da seleção do PNBE, ou seja, a intenção do estudo não é avaliar o programa, mas sim oferecer uma base analítica de onde outros estudos poderão partir. Essa análise contextual consiste na identificação da lógica que parece ordenar o processo de seleção e dos efeitos que a adoção dessa lógica acarreta ou pode acarretar para o processo. Para tanto, o texto encontra-se dividido em duas partes: uma primeira, em que se realiza uma leitura das etapas e de seus fundamentos, conforme os dois últimos editais²; e uma segunda, na qual se faz uma descrição mais detalhada da segunda etapa - a avaliação pedagógica das obras literárias - e seus critérios de seleção; sendo que cada parte encontra-se dividida em subpartes destinadas a orientar a leitura dos aspectos julgados mais relevantes para o contexto do $\mathrm{PNBE}^{3}$. Ao final, esperamos que a leitura proposta seja relevante para discussões sobre o PNBE não só porque ela buscará desvelar o modo de funcionamento do programa, como também porque pode assinalar, na análise das etapas e dos critérios adotados, os termos e limites da relação entre literatura e endereçamento escolar na formação de acervos para bibliotecas de escola pública.

\section{AS ETAPAS DO PNBE}

Depois que o PNBE retomou o eixo da formação do acervo da biblioteca e consolidou sua sistemática em 2006, os editais praticamente não sofreram alterações substanciais no que tange às etapas e critérios gerais do processo seletivo, antes um refinamento que foram tornando mais explícitos ou mais direcionados os propósitos da seleção. Dessa forma, tomando como base os editais do PNBE 2012 (Brasil, 2010) e PNBE 2013 (Brasil, 2011), verifica-se que são três as etapas da seleção: a triagem, a avaliação pedagógica e a compra das obras. Neste tópico, vamos apresentar a primeira e a última etapa e deixar para o tópico seguinte a segunda por se constituir a etapa central do processo.

${ }^{2}$ Adotamos os dois últimos editais com o objetivo de abranger todo o atendimento feito pelo PNBE, uma vez que o Programa alterna, como já destacamos, entre os anos pares e ímpares o atendimento aos anos iniciais do ensino fundamental, educação infantil e EJA e aos anos finais do ensino fundamental e ensino médio, respectivamente.

${ }^{3}$ Tendo em vista que se procura delinear a racionalidade dos editais e a fim de não cansar o leitor com sucessivas citações de trechos dos editais de 2012 e 2013, optamos por trabalhar o edital e seus anexos sem citações diretas, indicando entre parênteses os itens a que se referem nos editais. Para conferência de aspectos da análise feita, aconselhamos a leitura integral dos dois editais que se encontram disponíveis em Brasil, 2012. 


\subsection{A triagem}

Etapa que verifica os aspectos físicos e atributos editoriais das obras inscritas conforme determinado no edital, a triagem foi dividida em dois momentos no edital de 2012 (triagem e pré-análise) e passou a ser um só no edital de 2013. Aparentemente, deveria ser uma etapa com pouca interferência no processo seletivo. Todavia, quando se verifica que das 2111 obras inscritas, 468 foram retidas nesta etapa no PNBE 2013 (UFMG, 2012b), impedindo que façam parte da avaliação, compreende-se que se trata de uma etapa que influencia consideravelmente o resultado final da seleção.

Os critérios que orientam a triagem são, em sua maioria, de cunho técnico e documental, dizendo respeito às condições de participação das editoras e cumprimento de requisitos legais para compras governamentais. É o que se observa, por exemplo, nas exigências de que a editora não tenha sido declarada inidônea ou suspensa de licitar em órgão ou entidade da Administração Pública direta ou indireta (PNBE 2102, item 5.4.1 e PNBE 2013, item 5.7.) e não haja contradição entre os dados presentes no livro e os dados apresentados pela editora na documentação ou no sistema eletrônico do FNDE (PNBE 2102, item 6.2.7 e PNBE 2013, item 6.2.8.). Há, porém, critérios que vão além e apontam para a existência de outras lógicas no ordenamento do processo de aquisição das obras que não apenas aquelas de cunho legal ou técnico.

Um desses critérios é o número de obras a ser inscrito por editora. No edital do PNBE 2012, cada editor pode inscrever apenas 15 obras, com no máximo cinco para as categorias da educação infantil e EJA e dez para a categoria anos iniciais do ensino fundamental. No edital do PNBE 2013, por sua vez, poderiam ser inscritas até 12 obras no total, com um máximo de oito obras em cada segmento, isto é, os anos finais do ensino fundamental e o ensino médio. Nos dois editais está também prevista a exclusão de obras que sejam inscritas em mais de uma das categorias elencadas (PNBE 2102 e 2013, itens 6.2.2 e 6.2.3.).

Em princípio, a limitação do número de obras é medida relevante para evitar que compras governamentais desse vulto se concentrem em poucas empresas e termine por reduzir o tamanho e o funcionamento do mercado editorial. Além disso, a restrição possibilita que editoras de diferentes portes tenham chances reais de terem suas obras contempladas na seleção, o que efetivamente tem ocorrido no processo. Das 266 editoras inscritas em 2012, por exemplo, 112 tiveram obras selecionadas, ou seja, $42 \%$ do total. Além disso, 69 das editoras inscreveram apenas cinco livros ou menos dos 15 a que tinham direito, o que equivale a cerca de um quarto de editoras (26\%) pequenas ou com catálogo de poucos títulos: 
482 - Remate de Males 34.2

Quadro 1 - Quantidade de livros inscritos por editora

\begin{tabular}{|c|c|}
\hline $\begin{array}{c}\text { Quantidade de Livros } \\
\text { Inscritos }\end{array}$ & $\begin{array}{c}\text { Quantidades de } \\
\text { Editoras }\end{array}$ \\
\hline 15 livros & 39 \\
\hline 14 livros & 32 \\
\hline 13 livros & 20 \\
\hline 12 livros & 11 \\
\hline 11 livros & 8 \\
\hline 10 livros & 11 \\
\hline 9 livros & 14 \\
\hline 8 livros & 16 \\
\hline 7 livros & 13 \\
\hline 6 livros & 13 \\
\hline 5 livros & 15 \\
\hline 4 livros & 13 \\
\hline 3 livros & 21 \\
\hline 2 livros & 20 \\
\hline 1 livros & 20 \\
\hline TOTAL & $\mathbf{2 6 6}$ \\
\hline
\end{tabular}

Fonte: UFMG, 2012b.

No entanto, se o critério da restrição corresponder à lógica da proteção à concorrência, estímulo à competitividade e incentivo à livre iniciativa, ou seja, a ampliação do número de editoras na seleção e o fortalecimento do mercado editorial, ele precisa ir mais além. Nesse sentido, destaca-se a ausência de critérios que incentivem a produção literária regional e nacional. No primeiro caso, essa ausência termina por reforçar a região Sudeste como centro do mercado editorial brasileiro, seguida pela região Sul em termos mais modestos. No PNBE 2012, por exemplo, apenas duas editoras com obras selecionadas eram da região Nordeste (Colégio Claretiano Assoc. Benef. Ed - Salvador/BA e Conhecimento Editora - Fortaleza/CE) e nenhuma da região Norte.

No segundo, o efeito mais evidente é a forte presença de obras traduzidas no acervo. Nos dois casos, perde-se uma oportunidade singular de incentivar e reforçar a produção literária do País. Com as editoras concentradas no Sudeste, a chance de um escritor que mora no Norte ou no Nordeste ter sua obra publicada é bem menor do que aquela conferida a um escritor de São Paulo ou Rio de Janeiro, pois o seu círculo de reconhecimento precisaria ter alcance nacional para merecer 
a atenção de uma editora fora de sua região. Do mesmo modo, o excesso de obras traduzidas pode conduzir ao abandono do investimento no autor nacional, prejudicando as novas gerações de escritores e o sistema literário como um todo. Além disso, perde o leitor dessas regiões e do País de ter sua realidade cultural reapresentada pelo texto literário, um efeito considerável quando se sabe que as obras, presumivelmente, serão objeto de leitura em escolas de todo o Brasil.

Mesmo quando se considera apenas o aspecto econômico, essa lógica de participação ampla da triagem continua falhando em seu objetivo, uma vez que escapando dessa limitação as grandes casas editoriais multiplicam seus selos e agregam diferentes editoras, de forma que muitas obras são apenas nominalmente de editoras diferentes ${ }^{4}$, uma vez que "o edital do FNDE não restringe a participação de grupos editoriais com seus diferentes selos concorrendo de forma autônoma" (Paiva, 2012, p. 305). Inversamente, uma editora que explora um determinado nicho editorial, ou seja especializada em determinado tipo de publicação, fica prejudicada. O mesmo acontece com uma editora pequena, com um catálogo de poucos títulos. Neste caso, se não é prejudicada pela limitação do número de obras, perde na regra da impossibilidade de inscrever a mesma obra em outra categoria, sobretudo quando se considera que as distâncias entre as categorias não são tão nítidas em termos da relação entre a obra literária e o público leitor, como se pode observar na distinção feita entre categoria 1 e 2 do edital PNBE 2012:

\begin{abstract}
3.2.1. Categoria 1: para as instituições de educação infantil - etapa creche: 3.2.1.1. Textos em verso - quadra, parlenda, cantiga, trava-língua, poema; 3.2.1.2. Textos em prosa - clássicos da literatura infantil, pequenas histórias, textos de tradição popular; 3.2.1.3. Livros com narrativa de palavras-chave - livros que vinculem imagens com palavras; 3.2.1.4. Livros de narrativas por imagens - com cores e técnicas diferenciadas como: desenho, aquarela, pintura, entre outras; (...)

3.2.2. Categoria 2: para as instituições de educação infantil - etapa pré-escola: 3.2.2.1. Textos em verso - poema, quadra, parlenda, cantiga, trava-língua, adivinha; 3.2.2.2. Textos em prosa - clássicos da literatura infantil, pequenas histórias, teatro, textos da tradição popular; 3.2.2.3. Livros de narrativas por imagens (Brasil, 2010, p. 2, grifo nosso).
\end{abstract}

${ }^{4}$ Como exemplo, tome-se o caso do grupo editorial Ediouro, que consta nas obras selecionadas do PNBE 2013 com quatro diferentes denominações (Ediouro Pub. de Passatempos e Multimidia Ltda; Ediouro Publicações Ltda; Ediouro Gráfica e Editora Ltda; Ediouro Pub. de Lazer e Cultura Ltda), sendo composto também pelas editoras Nova Fronteira, Desiderata, Agir, Thomas Nelson Brasil e Nova Aguilar (http://www.ediouro.com.br/site/). 
Nessa mesma direção se inscreve a contraditória questão da proibição da aquisição de obras em língua portuguesa que estejam em domínio público (PNBE 2102, item 3.9.2 e PNBE 2013, item 3.12.2.). Aparentemente, a lógica de tal critério é a economicidade que consiste em não comprar aquilo que é, por natureza, gratuito. Um efeito positivo daí decorrente é que as obras inscritas tendem a apresentar a literatura viva, no sentido de ser uma literatura contemporânea ou produzida em um período de tempo mais próximo do público leitor. Todavia, como a restrição não vale para obras estrangeiras, a seleção passa a contemplar boa parte do cânone de outras literaturas enquanto ignora o seu próprio cânone. Mais que isso, como essas obras canônicas de outras literaturas já chegam sancionadas em termos de qualidade literária, as chances de serem aprovadas são maiores do que autores contemporâneos que ainda não conseguiram reconhecimento ou são estreantes, quer nacionais ou de outros países. Não surpreende, portanto, que as editoras invistam em inscrever esse tipo de obra e tenham logrado êxito em sua estratégia. Nos três acervos do ensino fundamental do PNBE de 2013, verifica-se, por exemplo, que a presença de obras de autoria estrangeira, adaptados ou originais, vai de $27 \%$ a $43 \%$ e dentro dessas obras de $46 \%$ a $56 \%$ estão em domínio público. Somados os três acervos, o resultado é que das 180 obras selecionadas, $37 \%$ são obras de autoria estrangeira e destas $49 \%$ em domínio público, como se pode ver na Tabela 1 abaixo e conferido mais detalhadamente no Quadro 4 que lhe segue.

\begin{tabular}{|c|c|c|c|c|c|}
\hline \multirow[t]{2}{*}{$\begin{array}{l}\text { Acervos } \\
\text { EF }\end{array}$} & \multirow{2}{*}{$\begin{array}{c}\begin{array}{c}\text { Obras } \\
\text { selecionadas }\end{array} \\
\text { Quantidade }\end{array}$} & \multirow{2}{*}{$\begin{array}{c}\text { Total de obras } \\
\text { estrangeiras }\end{array}$} & \multicolumn{3}{|c|}{$\begin{array}{l}\text { Obras estrangeiras em } \\
\text { domínio público }\end{array}$} \\
\hline & & & $\%$ & Quantidade & $\%$ \\
\hline I & 60 & 25 & $42 \%$ & 12 & $48 \%$ \\
\hline II & 60 & 16 & $27 \%$ & 9 & $56 \%$ \\
\hline III & 60 & 26 & $43 \%$ & 12 & $46 \%$ \\
\hline $\begin{array}{l}\text { Total de } \\
\text { obras }\end{array}$ & 180 & 67 & $37 \%$ & 33 & $49 \%$ \\
\hline
\end{tabular}

Fonte: Dados elaborados pelos autores a partir de lista divulgada no sítio do FNDE (Brasil, 2012). 
Quadro 2 - Obras estrangeiras e obras estrangeiras em domínio público

\begin{tabular}{|c|c|c|}
\hline \multicolumn{3}{|c|}{ LIVROS SELECIONADOS PNBE 2013} \\
\hline \multicolumn{3}{|c|}{ Acervo 1 - Anos finais do Ensino Fundamental } \\
\hline \multicolumn{2}{|r|}{ TÍTULO } & $\begin{array}{l}\text { DOMÍNIO } \\
\text { PÚBLICO }\end{array}$ \\
\hline 1 & A INVENÇÃO DE HUGO CABRET & NÃO \\
\hline 2 & ERA UMA VEZ À MEIA-NOITE & SIM \\
\hline 3 & FRRITT- FLACC & SIM \\
\hline 4 & A ILHA DO TESOURO & SIM \\
\hline 5 & O CARA & NÃO \\
\hline 6 & AS MELHORES HISTÓRIAS DAS MIL E UMA NOITES & SIM \\
\hline 7 & O DESAPARECIMENTO DE KATHARINA LINDEN & NÃO \\
\hline 8 & VIAGEM AO CENTRO DA TERRA & SIM \\
\hline 9 & COMANDANTE HUSSI & NÃO \\
\hline 10 & NINA & NÃO \\
\hline 11 & OS PEQUENOS VERDES E OUTRAS HISTÓRIAS & SIM \\
\hline 12 & A PEDRA NA PRAÇA & SIM \\
\hline 13 & HISTÓRIAS ARREPIANTES DE CRIANÇAS-PRODÍGIO & NÃO \\
\hline 14 & O DIÁRIO DE DAN & NÃO \\
\hline 15 & O FANTASMA DE CANTERVILLE & SIM \\
\hline 16 & VIAGEM NUMA PENEIRA & SIM \\
\hline 17 & DUELO & NÃO \\
\hline 18 & O ÔNIBUS DE ROSA & $\mathrm{NÃO}$ \\
\hline 19 & AS AVENTURAS DE TOM SAWYER & SIM \\
\hline 20 & ROBIN HOOD & SIM \\
\hline 21 & O CHAMADO DO MONSTRO & $\mathrm{NÃO}$ \\
\hline 22 & AVENTURAS DE ALICE NO SUBTERRÂNEO & SIM \\
\hline 23 & $\begin{array}{l}\text { WILLIAM SHAKESPEARE E SEUS ATOS DRAMÁTICOS } \\
\text { (MORTOS DE FAMA) }\end{array}$ & NÃO \\
\hline 24 & CHARLES DARWIN: O SEGREDO DA EVOLUÇÃO & NÃO \\
\hline 25 & AS AVENTURAS DE MAX E SEU OLHO SUBMARINO & NÃO \\
\hline \multicolumn{3}{|c|}{ Acervo 2 - Anos finais do Ensino Fundamental } \\
\hline 1 & ANNE DE GREEN GABLES & SIM \\
\hline 2 & OS LIVROS QUE DEVORARAM MEU PAI & NÃO \\
\hline 3 & MEU CORAÇÃO É TUA CASA & SIM \\
\hline 4 & MARY SHELLEY: O MISTÉRIO DA IMORTALIDADE & NÃO \\
\hline
\end{tabular}


486 - Remate de Males 34.2

\begin{tabular}{|c|c|c|}
\hline 5 & A FAMÍLIA PÂNTANO 4 - APARÊNCIAS & NÃO \\
\hline 6 & AS MIL E UMA NOITES & SIM \\
\hline 7 & O FLAUTISTA DE HAMELIN & SIM \\
\hline 8 & CONTOS CLÁSSICOS DE VAMPIRO & SIM \\
\hline 9 & O DOENTE IMAGINÁRIO & SIM \\
\hline 10 & GATOS GUERREIROS - NA FLORESTA & NÃO \\
\hline 11 & OS NOIVOS & SIM \\
\hline 12 & O PÁSSARO DE FOGO CONTOS POPULARES DA RÚSSIA & SIM \\
\hline 13 & CARA SENHORA MINHA AVÓ & NÃO \\
\hline 14 & MIL COISAS PODEM ACONTECER & NÃO \\
\hline 15 & AMANHÃ VOCÊ VAI ENTENDER & NÃO \\
\hline 16 & UEBRA-NOZES E CAMUNDONGO REI & SIM \\
\hline \multicolumn{3}{|c|}{ Acervo 3 - Anos finais do Ensino Fundamental } \\
\hline 1 & CORALINE & NÃO \\
\hline 2 & O GUARANI & SIM \\
\hline 3 & À ESQUERDA, À DIREITA & NÃO \\
\hline 4 & O SENHOR DOS LADRÕES & NÃO \\
\hline 5 & O LIVRO DOS DRAGÕES & NÃO \\
\hline 6 & MÉDICO À FORÇA & SIM \\
\hline 7 & O FANTASMA DE CANTERVILLE & SIM \\
\hline 8 & A JORNADA & NÃO \\
\hline 9 & MOBY DICK & SIM \\
\hline 10 & RAUL TABURIN & NÃO \\
\hline 11 & A PRINCESA FLUTUANTE & SIM \\
\hline 12 & A FÁBRICA DE ROBÔS & SIM \\
\hline 13 & ERA UMA VEZ ESOPO & SIM \\
\hline 14 & ENGENHOSO FIDALGO DOM QUIXOTE DE LA MANCHA & SIM \\
\hline 15 & A CAMINHO DE CASA & $\mathrm{NÃO}$ \\
\hline 16 & OS GÊMEOS DO POPOL VUH & NÃO \\
\hline 17 & A VOLTA ÀS AULAS DO PEQUENO NICOLAU & $\mathrm{NÃO}$ \\
\hline 18 & O DIÁRIO DE GIAN BURRASCA & SIM \\
\hline 19 & VOCẾ É LIVRE! & NÃO \\
\hline 20 & EMIL E OS DETETIVES & NÃO \\
\hline 21 & HISTÓRIAS DE BICHOS & SIM \\
\hline 22 & JACQUES COUSTEAU: O MAR, OUTRO MUNDO & NÃO \\
\hline
\end{tabular}




\begin{tabular}{|c|l|c|}
\hline 23 & NO REINO DA PONTUAÇÃO & SIM \\
\hline 24 & O LIVRO SELVAGEM & NÃO \\
\hline 25 & FANTÁSTICA FÁBRICA DE CHOCOLATE & NÃO \\
\hline 26 & TRISTÃO E ISOLDA & SIM \\
\hline
\end{tabular}

Fonte: Elaboração dos autores - UFMG, 2012b.

Por fim, há a questão dos gêneros literários. Segundo o edital, não serão avaliadas as obras cujo gênero literário seja diverso dos previstos no edital (PNBE 2102, Anexo I, A 4 e PNBE 2013, Anexo I, A 5) 5 . A lógica que parece reger esse critério éa da fidegnidade, ou seja, impede-se com esse dispositivo que se compre um livro diferente daquele preconizado pelo edital. No entanto, qualquer estudante de Letras percebe que a classificação dos gêneros adotada pelo MEC é inadequada, pois mistura elementos de ordem diversa em categorizações superpostas. É o caso, por exemplo, da distinção genérica de texto em prosa e texto em verso presente no edital do PNBE de 2012 supostamente para recobrir os gêneros do registro poético e os gêneros do registro narrativo do discurso literário ou, ainda, a divisão entre poesia e ficção. Por um lado, os termos são tão genéricos que pouco discriminam, daí que se recorra a uma exemplificação. Por outro, a exemplificação pode contrariar o termo que o recobre, como acontece com a suposição de que o teatro seja sempre em prosa ou que clássicos da literatura infantil e textos

${ }^{5}$ No edital do PNBE 2012, esses gêneros foram: a) categoria 1 (educação infantil - etapa creche), textos em verso - quadra, parlenda, cantiga, trava-língua, poema; textos em prosa - clássicos da literatura infantil, pequenas histórias, textos de tradição popular; livros com narrativa de palavras-chave - livros que vinculem imagens com palavras; livros de narrativas por imagens - com cores e técnicas diferenciadas como: desenho, aquarela, pintura, entre outras; b) categoria 2 (educação infantil - etapa pré-escola) textos em verso - poema, quadra, parlenda, cantiga, trava-língua, adivinha; textos em prosa - clássicos da literatura infantil, pequenas histórias, teatro, textos da tradição popular; livros de narrativas por imagens; c) categoria 3 (anos iniciais do ensino fundamental) textos em verso - poema, quadra, parlenda, cantiga, trava-língua, adivinha; textos em prosa - pequenas histórias, novela, conto, crônica, teatro, clássicos da literatura infantil; livros de imagens e livros de histórias em quadrinhos, dentre os quais se incluem obras clássicas da literatura universal, artisticamente adaptadas ao público dos anos iniciais do ensino fundamental; d) categoria 4 (educação de jovens e adultos) textos em verso - poema, cordel, provérbios, ditos populares; textos em prosa - romance, novela, conto, crônica, teatro, biografia, diário, relato de experiência, texto de tradição popular; livros de imagens e livros de histórias em quadrinhos, dentre os quais se incluem obras clássicas da literatura universal, artisticamente adaptadas ao público de educação de jovens e adultos (ensino fundamental e médio). No edital do PNBE 2013, os gêneros literários para as duas categorias foram: poema; conto, crônica, novela, teatro, texto da tradição popular; romance; memória, diário, biografia, relatos de experiências; obras clássicas da literatura universal; livros de imagens e livros de histórias em quadrinhos. 
da tradição popular não possam ter registro poético. Não surpreende, portanto, que os editores se percam nessas classificações e as obras sejam inscritas quase que independentemente do disposto no edital. Afinal, como distinguir em uma triagem, um romance de uma novela? Ou um romance de uma obra clássica da literatura universal?

\subsection{A compra}

Assim como a triagem, a lógica da compra das obras segue naturalmente o que está disposto em Lei para as compras governamentais, isto é, as compras devem ser orientadas pelos princípios da economicidade, isonomia, legalidade, impessoalidade, moralidade, publicidade, eficiência e legitimidade, todos eles harmonizados no sentido de garantir a seleção da proposta mais vantajosa para a administração pública. No caso do PNBE, tais princípios são naturalmente obedecidos, mas não sem consequências.

Uma delas é que, como se trata de uma compra volumosa, o ganho em escala e a eliminação de intermediários leva o preço individual do livro para patamares muito mais baixos do que aqueles encontrados em livrarias. Basta comparar o preço pago pelo governo pela obra unitária e o preço de capa de um livro selecionado para compreender como são aplicados os legítimos preceitos da economicidade e da eficiência, como se pode verificar na Tabela 2 abaixo:

Tabela 2 - Ganho em escala

\begin{tabular}{|c|c|c|c|c|}
\hline Título da obra & Editora & $\begin{array}{c}\text { Quantidade } \\
\text { PNBE - 2012 }\end{array}$ & $\begin{array}{c}\text { Valor unitário } \\
\text { PNBE - 2012 }\end{array}$ & $\begin{array}{c}\text { Valor unitário } \\
\text { Livraria cultura }\end{array}$ \\
\hline 10 galinhas & $\begin{array}{c}\text { Editora de } \\
\text { Cultura Ltda }\end{array}$ & 19.094 & $\mathrm{R} \$ 4,14$ & $\mathrm{R} \$ 25,00$ \\
\hline 2 patas e 1 tatu & $\begin{array}{c}\text { Gráfica e } \\
\text { Editora } \\
\text { Posigraf SA }\end{array}$ & 19.094 & $\mathrm{R} \$ 4,00$ & $\mathrm{R} \$ 27,80$ \\
\hline $\begin{array}{c}\text { Achados e } \\
\text { perdidos }\end{array}$ & $\begin{array}{c}\text { Roda Viva } \\
\text { Editora Ltda }\end{array}$ & 19.094 & $\mathrm{R} \$ 5,37$ & $\mathrm{R} \$ 33,50$ \\
\hline
\end{tabular}

Fonte: Elaboração dos autores - dados Brasil, 2012; Livraria Cultura, 2012.

Todavia, ainda que pertinentes na perspectiva da compra governamental, os preços baixos pagos têm levado os editores a sutilmente escolher em seus catálogos para inscrição não apenas as obras que possuem as características adequadas do ponto de vista literário, mas também aquelas que melhor se ajustam ao aspecto econômico da sua 
produção física. Ainda que seja uma realidade para todos os segmentos, são os livros infantis que mais sofrem com esse tipo de racionalidade. As obras de capa dura ou com recursos variados de edição gráfica que são encontradas fácil e profusamente nas livrarias dos shoppings centers e nos catálogos das editoras não se fazem presentes na mesma proporção na inscrição do PNBE (Paiva, 2012).

Outra consequência da compra ser feita em grandes volumes em uma negociação direta entre o FNDE e as editoras é que alija do processo o docente ou o bibliotecário da escola. Nesse sentido, ao contrário do Programa Nacional do Livro Didático em que o professor e a escola selecionam o livro que desejam usar, o PNBE usa como critério de compra e distribuição o número de alunos por escola. Dessa forma, conforme o edital PNBE 2012, uma escola de EJA com 50 alunos recebe um acervo, uma escola do mesmo segmento com mais de 50 alunos recebe dois acervos, sendo cada acervo constituído por um mesmo número de diferentes obras. No entanto, a participação do docente foi contemplada no edital do PNBE 2005, o qual possibilitava no item $7 \cdot 4$. que professores escolhessem o acervo de seu interesse para o trabalho em sala de aula ou na biblioteca:

\footnotetext{
7.4. Da Escolha dos acervos pelas escolas Serão disponibilizadas às escolas Informações sobre os acervos selecionados. Os professores, em consenso, e com base na análise das informações sobre as obras, escolherão o acervo mais adequado à proposta de formação de leitores, desenvolvida pela escola. Após a escolha, ficará a cargo do diretor da escola o preenchimento e encaminhamento do formulário específico ao FNDE, via Internet ou correio (Brasil, 2004, p. 6).
}

Aparentemente, a troca desse critério pelo número de alunos por escola conforme o censo escolar do INEP se deu por razões de logística na distribuição dos livros e a referida economia de escala, posto que o número de exemplares é conhecido antecipadamente pelo governo, facilitando a negociação. O ganho representado pela lógica da economicidade, porém, parece se chocar com a lógica da eficiência que a participação do professor na seleção poderia representar para o uso dos livros nas escolas, tal como demonstram estudos relativos ao PNBE 2005 em Belo Horizonte (Montuani, 2009) e alguns municípios do Rio de Janeiro (Paiva, 2008).

\section{A AVALIAÇÃO PEDAGÓGICA DAS OBRAS LITERÁRIAS}

Segunda etapa do processo de seleção, a avaliação pedagógica das obras literárias está configurada em um anexo que orienta a avaliação propriamente dita ao estabelecer critérios relativos à qualidade do texto, 
adequação temática e projeto gráfico. Como esses aspectos já foram detalhadamente discutidos em outros textos, tanto em uma perspectiva sincrônica (Cosson, 2012), quanto em uma perspectiva diacrônica, comparando-se diferentes editais do PNBE entre os anos de 2005 e 2012 (Fernandes e Cordeiro, 2012; Paiva, 2012), além de seu funcionamento operacional (Bahia, 2012, Paiva et al, 2008), focaremos nossa análise em pontos que colocam em discussão a lógica de sua organização.

\subsection{O endereçamento escolar}

Dificilmente uma cultura humana deixará de apresentar um estreito e positivorelacionamentoentreliteraturaeeducaçãoquandocompreendidas como atividades sociais que organizam e dão sentido à vida em sociedade. Em outras palavras, enquanto compreendida no sentido lato dado por Candido acima, literatura e educação são parceiras na definição do que é ser humano. Todavia, quando se estreita para a formação do leitor, tal como é trabalhada na escola formal, essa relação perde em boa parte o seu caráter positivo ou de mútuo benefício. Para a maioria dos estudiosos da literatura, como Zilberman no texto já citado, isso acontece porque a literatura deixa de ser literatura para ser instrumento da educação e tal subordinação, ironicamente, retira da literatura as qualidades de formação que justificam e fundamentam a parceria entre elas ao longo da história. É por essa razão que uma das maiores preocupações presente nos editais do PNBE é justamente assegurar que essa subordinação não aconteça. Daí que sejam eliminadas do processo de seleção obras que sejam predominantemente didáticas, informativas ou de referência. A questão é ainda reforçada pela igual eliminação de obras que possuam lacunas ou espaços de preenchimento em semelhança ao livro didático, pois além de impedir um uso coletivo, podem também conduzir a leitura do aluno para um fim pedagógico (PNBE 2102, itens 3.9.3 e 3.9.4 e PNBE 2013, itens 3.12.3 e 3.12.4.).

Afastada a ameaça do didatismo que ronda a relação da literatura com a educação, fica mais fácil entender em que consiste a lógica pedagógica do PNBE. Um de seus principais componentes é a relação entre a maturidade do leitor-aluno e o leitor implícito com que a obra dialoga, uma questão que talvez seja mais bem entendida no âmbito da diversidade dos textos literários, tal como abordaremos no próximo tópico. Aqui julgamos pertinente destacar a configuração física da obra ou o que chamamos de edição escolar. Trata-se de conceber a obra com um uso preferencial - sendo importante que não seja exclusivo para manter seu estatuto de texto independente - na escola ou por leitores em formação. 
É isso que buscam as exigências de que as obras tragam os elementos de autoria e registro claramente identificados, o que facilita sua catalogação na biblioteca e circulação entre os leitores iniciantes; assim como que apresentem paratextos que contextualizem o autor e o próprio texto no universo literário, além de outras informações que sejam relevantes para o público escolar (PNBE 2102, item 3.8 e Anexo II, 1.3; e PNBE 2013, item e 6.2.5 e Anexo II, 1.3.). Esses dados são importantes tanto para as obras do passado, cujos paratextos devem ajudar o leitor a compreender porque elas continuam sendo atuais e merecem ser lidas, quanto para as obras do presente, por se constituírem em uma apresentação do autor estreante ou da forma como uma nova temática e recursos expressivos são incorporados à escrita da literatura. Trata-se, pois, dentro da lógica pedagógica, de uma edição voltada para o uso na escola, mas não didática, ou seja, uma obra que seja voltada para o público escolar, embora não necessariamente para a sala de aula.

Para além da dificuldade dos editores de produzir obras com esse equilíbrio entre escola e sala de aula, como mostram obras de excelente qualidade literária erroneamente acompanhadas com sugestões de atividades ou com paratextos pouco elucidativos, o efeito mais evidente dessa lógica pedagógica é exatamente a melhoria da edição, ou seja, temos hoje obras que são devidamente introduzidas ao leitor, como mostram os livros infantis e as maneiras criativas que os paratextos são constituídos, além dos clássicos que necessariamente devem ser acompanhados de paratextos que explicitem essa condição. Tomemos, como exemplo, o livro As aventuras de Tom Sawyer, de Mark Twain, selecionado no PNBE 2012. Nele se encontram vários paratextos que contextualizam efetivamente o autor e a obra: São Petersburgo, Missouri: uma outra terra do nunca, do tradutor Luiz Antonio Aguiar; Mark Twain, o prestidigitador, o extravagante, texto biográfico; Momento histórico; e Momento Literário.

Um efeito curioso do endereçamento escolar é a sobrevivência de certos gêneros da tradição popular, quer como registro, quer como reconto. Aqui a distância entre o didático e o literário é tão tênue que mal esconde o aproveitamento que tais gêneros têm no processo educacional. É o caso da quadra, parlenda, cantiga, trava-língua e adivinha que, sendo gêneros de registro basicamente oral, circulam na escola intimamente ligados à alfabetização. Também as lendas e as narrativas míticas em geral cumprem esse papel, servindo de ponte entre a formação do leitor e a introdução a culturas não hegemônicas ou de outros povos, a exemplo dos indígenas (Silveira e Bonin, 2012). 
Outro efeito que merece um estudo a parte é a transformação de um gênero ou um registro específico em um modo ou meio de expressão, fenômeno que escapa dos limites do PNBE, mas que no Brasil está intensamente relacionado às compras governamentais. É o caso do cordel e das histórias em quadrinhos que se multiplicam em muitas direções, incorporando temas e propostas estilísticas que pertencem a outras tradições. Não se trata aqui apenas do uso dos recursos do cordel e das histórias em quadrinhos para veicular conteúdos disciplinares, uma prática que é bem conhecida, mas que retira da obra o seu caráter literário. Nem apenas da transposição, seja com adaptação, versão ou reescritura, para um novo registro de obras como romances, contos e poemas, usualmente clássicas. Nem o reconhecimento das histórias em quadrinhos como expressão artística autônoma (Bahia, 2012). O fenômeno vai mais além quando faz do cordel e das histórias em quadrinhos um modo de expressão literária que pode "traduzir" virtualmente qualquer coisa para seus registros, desde um episódio de Os Lusíadas, como em A História de Inês de Castro ou A dama lourinha que, depois de morta, virou rainha, de Fábio Sombra, até a biografia de Nietzsche, a exemplo de Nietzsche em $H Q$ de Michel Onfray. Observe-se que essa apropriação é justificada, na maioria das vezes, pela necessidade de introduzir a obra para o leitor em formação ou aproximá-lo das grandes obras e temas, ou seja, conforme a lógica pedagógica que determina o endereçamento e a edição escolar desses textos.

\section{2. $O$ conceito de literatura}

Em se tratando da avaliação pedagógica de obras literárias, o principal critério do PNBE é que as obras selecionadas sejam literárias (PNBE 2102 e 2013, item 3.1.). A definição do que seja literatura, entretanto, não é uma tarefa fácil, sobretudo no âmbito de uma seleção que envolve textos extremamente diversificados em seu direcionamento para leitores de todas as idades, posto que o Programa, como se sabe, atende desde creches até o ensino médio, incluindo a educação de jovens e adultos. Neste caso, os limites do literário parecem ser circunscritos a partir de três lógicas superpostas.

A primeira delas é a lógica do objeto estético, ou seja, o texto tem que se sustentar enquanto objeto estético e não por exercer outras funções. É isso que está inscrito nos critérios que recusam obras cujos fins sejam didáticos, doutrinários ou panfletários, não importa quão nobre seja a causa e o ensinamento que defendam, e que apresentem moralismos e conduzam explicitamente a opinião do leitor (PNBE 2102, item 3.9.3 
e PNBE 2013, item 3.12.3.). Com isso, não se compreende que os textos literários devam ser assépticos, muito menos que não apresentem em maior ou menor grau um posicionamento político, uma mensagem, porque o que as move é o conflito, logo todas procuram conduzir o leitor. Além disso, há certos gêneros, como as fábulas, que contêm por definição uma moral, e as lendas, que por serem narrativas cosmogônicas foram elaboradas para explicar um fenômeno natural ou ensinar algo sobre o mundo. A questão, então, não é a presença ou ausência de condução ou ensinamento, mas a maneira como é feita e o tipo dessa condução ou ensinamento. Se o compromisso da obra não é com o literário ou ele não ocupa o primeiro plano da obra, se a obra não se constitui como objeto estético em primeiro lugar, ela não deve ser considerada como literária.

A segunda é a lógica da qualidade que, como destacou Zilberman no texto citado acima, é elemento crucial para que a literatura cumpra seu papel na formação do leitor. $\mathrm{O}$ anexo II que orienta a avaliação pedagógica das obras literárias nos editais de 2012 e 2013 tem um item todo dedicado à qualidade do texto. Dentro dele, o critério mais revelador dessa lógica talvez seja aquele que busca excluir da seleção obras constituídas de clichês ou estereótipos saturados. Em um entendimento teórico, trata-se de selecionar obras que se apresentem como originais ou, pelo menos, que contribuam para uma nova forma de ver e dizer o mundo. Na prática, entretanto, a questão é mais delicada. Há que se considerar, por exemplo, que o clichê e o estereótipo não podem ser dissociados dos estilos de época, dos gêneros e da história do leitor. Uma obra que simplesmente reproduz os elementos estilísticos do Romantismo nos dias atuais pode ser vista como clichê, mas um texto daquele período com os mesmos elementos não. Obras de um gênero fortemente marcado, como a fábula ou $o$ romance policial, podem parecer estereotipados por apresentar estrutura e personagens similares. Para o leitor que nunca leu um texto daquele estilo ou gênero, os clichês e os estereótipos podem passar despercebidos. Além do mais, a repetição ou a previsibilidade de certos textos são relevantes para os leitores infantis ou neoleitores jovens e adultos, que são parte do público a quem se destinam os acervos do PNBE. Percebe-se, com isso, que a lógica da qualidade literária não pode ser pensada apenas em relação a elementos textuais, recursos expressivos e trabalho estético com a linguagem, mas também com base em elementos intertextuais e contextuais que constituem o texto enquanto obra literária.

A terceira é a lógica da diversidade das obras que recobre quatro critérios distintos ligados diretamente à formação do leitor (PNBE 2102 e 2013, Anexo II, 1.1. e 1.2.). O primeiro deles é a diversidade temática que se preocupa tanto com a presença de obras com temas diferentes quanto 
de obras com temas adequados aos interesses dos diferentes leitores. O segundo é a diversidade de representação, ou seja, buscam-se obras que tratem das diversas e diferentes realidades da sociedade brasileira, compreendendo os aspectos socioeconômicos, culturais, ambientais e históricos. O terceiro éa diversidade de formas e gêneros, demandando que o acervo seja composto de tipos de texto diferentes. O quarto éa diversidade de níveis de complexidade de elaboração das obras, considerando-se tanto os diferentes leitores a que se destinam as obras, conforme os segmentos escolares, como também as diferenças existentes entre leitores dentro do seu segmento, implicando faixa etária e competência literária.

Consideradas as lógicas no conjunto, pode-se dizer que, excetuandose a condição de objeto estético, o conceito de literatura do PNBE é de inclusão. $\mathrm{O}$ efeito que daí resulta é um acervo constituído por uma ampla variedade de obras. O acervo 2, da categoria 3, destinado ao segmento anos iniciais do ensino fundamental do PNBE 2012, por exemplo, foi composto de narrativas da literatura infantil brasileira (Até as princesas soltam pum) e de outros países como Índia (Elefantes nunca esquecem), Reino Unido (Como treinar se dragão), Chile (Insônia) e Espanha (O menino que comia lagartos); narrativas de metaficção (O menino que espiava para dentro) e recontos da tradição popular (Histórias de bichos brasileiros); fábulas de Esopo e La Fontaine, recontadas pela turma do Sítio do Picapau Amarelo (Fábulas) e uma "continuação" do clássico Alice no país das maravilhas (Alice no telhado); uma espécie de bestiário que usa máquinas no lugar de animais (O livro das máquinas malukas) e uma parlenda (A casa das dez furunfelhas); umlivrodepoemasinfantis(Dezenovepoemas desengonçados) e um poema clássico do nosso cancioneiro (Trem de Alagoas); uma paródia em forma de teatro ( $O$ reino adormecido) e um livro de imagens ( $A$ pequena marionete); entre outros gêneros e formatos literários.

O resultado eclético dessa composição pode parecer algo incoerente se olhado do ponto de vista canônico ou da disciplina literatura, mas está perfeitamente de acordo com as lógicas do objeto estético, da qualidade e da diversidade que circunscrevem os limites do literário no âmbito da seleção do PNBE. Afinal, trata-se de uma avaliação pedagógica de obras literárias que tem como horizontes, tal como destacamos no início, o direito à literatura e a formação do leitor.

\subsection{Os princípios do Estado}

Como é um programa governamental e parte de uma política pública, o PNBE não poderia deixar de levar em consideração os princípios constitucionais do estado brasileiro. Tais princípios estão colocados, 
explicitamente, na recusa de obras de cunho religioso, uma vez que o estado é laico e não deve patrocinar qualquer credo (PNBE 2102, item 3.9.3 e PNBE 2013, item 3.12.3.).

A lógica republicana que justifica a exclusão das obras decunho religioso é facilmente absorvida no processo seletivo, pois embora a literatura tenha incorporado no passado obras que pertenciam a um credo específico, como Os Sermões, de Padre Vieira, a produção religiosa atual já se desligou do campo literário. Há, entretanto, uma outra face do republicanismo que, embora não esteja explicitamente colocada nos critérios dos editais, tem gerado reações em relação à seleção do PNBE. Trata-se da temática sexual e de violência, sobretudo quando representadas de forma realista. Um caso polêmico foi a seleção de Um contrato com Deus, de Will Eisner, no PNBE de 2009, para o acervo destinado aos alunos do ensino médio. Considerado inadequado por conter temática sexual, o livro sofreu censura no Rio Grande do Sul e em cidades de São Paulo e do Paraná, inclusive uma recomendação do Ministério Público do Estado de Goiás para que essa e outras obras do acervo do PNBE fossem recolhidas (Ribeiro, 2009; Gonzatto, 2009; MPEG, 2009). O MEC e intelectuais ligados aos quadrinhos reagiram argumentando que a obra possuía reconhecido valor artístico e que os livros seriam devidamente mediados por professores ou bibliotecários (Ramos, 2009). Passado o momento da polêmica, se não há dúvidas de que as obras sofreram diferentes formas de censura, não menos certo é que a lógica republicana da seleção se perdeu em meio às preocupações políticas da questão. No caso, se, por um lado, é dever de o Estado fornecer condições para que o aluno tenha acesso a diversas temáticas e representações literárias da sociedade, incluindo naturalmente o tema da sexualidade; por outro, é direito dos pais, como responsáveis pela formação moral dos filhos, determinar o que podem ou não ler. As bibliotecas das escolas públicas devem atender a todos os alunos, sejam eles filhos de pais liberais ou conservadores em relação a temáticas sexuais. As famílias devem ser ouvidas pelas escolas no que tange à orientação moral dos filhos. Por isso nem o Estado pode renunciar a seus fins públicos, nem a família renunciar a seus deveres parentais, o que é preciso é que os princípios e os critérios da seleção das obras sejam claramente explicitados para que a lógica republicana do interesse coletivo seja compreendida e que os direitos individuais sejam respeitados. Nada disso passa pelos mecanismos da censura, mas sim pelo diálogo que deveria ser a base para qualquer processo formativo, seja em casa, seja na escola.

A lógica democrática que exclui da seleção obras preconceituosas e discriminatórias, o que iria de encontro ao preceito da igualdade de todos perante a lei, sem distinções, por sua vez, gerou uma polêmica com efeito similar, porém bem mais acirrada. Neste caso, o centro da discussão foi o livro As caçadas de Pedrinho, de Monteiro Lobato, selecionado para um acervo 
do PNBE 2010. Denunciado por racismo na representação de personagens negras como Tia Nastácia, a obra foi objeto de um parecer do Conselho Nacional de Educação que recomenda a inclusão de uma nota explicativa contextualizando o livro em seu momento histórico. A solução conciliatória da nota para, de um lado, evitar o anacronismo de condenar uma obra por conter os preconceitos de sua época, e, de outro lado, ignorar as expressões racistas presentes na obra, não conseguiu serenar os ânimos. Os defensores de Lobato tomam o valor estético como absoluto e seus acusadores exigem a exclusão da obra do acervo do PNBE. A discussão entre surdos, que é típico das polêmicas, ainda está em curso. A tentativa de conciliação feita noâmbito do Supremo Tribunal Federal entre o MEC e o Instituto de Advocacia Racial e Ambiental (Iara) para discutir a ação que questiona o parecer foi infrutífera (Vieira, 2012). Um efeito imediato da questão foi um debate público sobre racismo no Brasil com posicionamentos os mais diversos. Nesse sentido, a lógica democrática, ainda que por meio transverso, está se fazendo presente para além do PNBE, pois é próprio da democracia o direito de se discutir e defender o que se julga correto à luz pública.

Um outro efeito igualmente positivo deverá ser um maior cuidado do MEC com as questões do racismo e da sexualidade na seleção das obras do PNBE. Espera-se que esse cuidado seja feito em direção a um maior conhecimento dos mecanismos da representação literária, assim como um aprofundamento das lógicas republicana e democrática. É dessa maneira que a seleção feita pelo PNBE continuará a cumprir e aprimorar o seu objetivo de oferecer a alunos e professores do sistema público de ensino o acesso à cultura, "de forma a contribuir para a construção de referencias (sic) éticos e estéticos e de ampliar a visão de mundo, formando, assim, indivíduos independentes e críticos, em interação com uma sociedade cidadã" (Brasil, 2010, p. 22).

\section{LITERATURA E ENDEREÇAMENTO ESCOLAR}

Menos que uma conclusão e mais uma proposta para a continuidade da reflexão, encerramos essa análise contextual lembrando que, se a literatura e a educação possuem uma longa história em comum, nem por isso a seleção de obras literárias para uso escolar deixa de enfrentar desafios.

Em primeiro lugar porque não se pode esquecer que se trata de uma seleção entre outras tantas seleções, uma vez que recebe o que já foi duplamente selecionado pelo mercado editorial e será objeto de seleções de bibliotecários, professores e alunos na escola. A seleção do PNBE é, por assim dizer, um filtro criado pelo governo para atender a 
sua política de formação dos acervos das bibliotecas escolares. Como é possível entrever pelas lógicas e efeitos expostos acima, esse filtro não opera em termos exclusivamente literários, nem mesmo pedagógicos, mas também por meio de mecanismos econômicos e políticos. A necessidade de combinar várias lógicas na composição e aquisição do acervo é um desafio a ser enfrentado para que se mantenha o foco na literatura e na formação do leitor como elementos basilares do processo seletivo.

Depois, ainda que se tomem todos os cuidados de não submeter o literário ao pedagógico e que a literatura seja concebida em um sentido amplo, como as lógicas subjacentes aos critérios adotados nos editais do PNBE parecem informar, mesmo assim o processo seletivo precisa revisar constantemente em que consiste o endereçamento escolar que propõe. $\mathrm{O}$ desafio aqui é não deixar que a preocupação com o valor estético oblitere a necessidade de atender a formação do leitor e vice-versa, mantendo o equilíbrio entre a diversidade das obras e a qualidade literária.

Por fim, tão importante quanto compreender que se trata de uma seleção de seleção e que é preciso manter o equilíbrio entre literatura e educação no endereçamento escolar, é permanecer aberto às ilimitadas possibilidades que o texto literário tem de se configurar, a fim de que a força de liberdade que a literatura nos oferece não se perca na obediência cega a critérios definidos a priori. Para tanto, cumpre ter sempre em mente o desafio que é avaliar pedagogicamente obras literárias, até porque como lembra Peltason (2007) em relação ao valor literário na epígrafe deste texto, se não há avaliação desinteressada ou livre de qualquer constrição, nem por isso podemos deixar de lado a acurácia e o princípio de justiça que devem governar todo julgamento.

\section{REFERÊNCIAS BIBLIOGRÁFICAS}

BAHIA, Márcio. A legitimação cultural dos quadrinhos e o Programa Nacional Biblioteca da Escola: uma história inacabada. Educação, Porto Alegre, v. 35, n. 3, p. 340-351, set./ dez. 2012.

BERENBLUM, Andrea e PAIVA, Jane. Por uma política de formação de leitores. Brasília: Ministério da Educação, Secretaria de Educação Básica, 2006.

BRASIL. Ministério da Educação. Fundo Nacional de Desenvolvimento da Educação. Edital de convocação para o processo de inscrição e avaliação de obras de literatura para o Programa Nacional Biblioteca da Escola - PNBE 2012. Brasília, 2010. Disponível em: < http://www.fnde.gov.br/index.php/be-consultas >. Acesso em: 03 out. 2012. 
BRASIL. Ministério da Educação. Fundo Nacional de Desenvolvimento da Educação. Edital de convocação para inscrição e seleção de obras de literatura para o Programa Nacional Biblioteca da Escola - PNBE 2013. Brasília, 2011. Disponível em: <http:// www.fnde.gov.br/index.php/be-consultas>. Acesso em: 03 out. 2012.

BRASIL. Ministério da Educação. Fundo Nacional de Desenvolvimento da Educação. Biblioteca da Escola. Disponível em: <http://www.fnde.gov.br/index.php/ programas-biblioteca-da-escola>. Acesso em: 11 nov. 2012.

BRASIL. Ministério da Educação. Fundo Nacional de Desenvolvimento da Educação. Edital de Convocação para inscrição de obras de literatura no processo de avaliação e seleção para o Programa Nacional Biblioteca da Escola - PNBE 2005. Disponível em: <http://www.fnde.gov.br/index.php/programas-biblioteca-da-escola >. Brasília, 2004. Acesso em: 03 out. 2012.

BRASIL. Ministério da Educação. Secretaria de Educação Básica. A política de formação de leitores e o PNBE - Programa Nacional Biblioteca da Escola. Brasília, 2009. Disponível em: < http://portal.mec.gov.br/seb >. Acesso em: 11 jan. 2012.

CANDIDO, Antonio. O direito à literatura. In: Vários Escritos. $3^{\underline{a}}$ ed. São Paulo: Duas Cidades, 1995.

COSSON, Rildo. Avaliação pedagógica de obras literárias. Educação, Porto Alegre, v. 35, n. 3, p. 308-318, set./dez. 2012.

FERNANDES, Célia R. D. e CORDEIRO, Maisa B. da S. Os critérios de avaliação e seleção do PNBE: um estudo diacrônico. Educação, Porto Alegre, v. 35, n. 3, p. 319-328, set./ dez. 2012.

GONZATTO, Marcelo. Pedofilia, estupro e adultério são temas para estudante? Zero Hora, 19 jun. 2009. Disponível em: < http://zerohora.clicrbs.com.br/pdf/11044426.pdf> Acesos em 10 out. 2012.

LAJOLO, Marisa. Literatura infantil brasileira e estudos literários. Estudos de Literatura Brasileira Contemporânea, Brasília, n. 36, p. 97-110, julho-dez. 2010.

LIVRARIA Cultura. Livros. Disponível em: <http://www.livrariacultura.com.br/scripts/ index.asp> Acesso em 10 out. 2012.

MONTUANI, Daniela F. B. O PNBE/2005 na Rede Municipal de Ensino de Belo Horizonte: uma discussão sobre os possíveis impactos da política de distribuição de livros de literatura na formação de leitores. Belo Horizonte: UFMG, FE, 2009. Dissertação (Mestrado).

MPEG. Ministério Público do Estado de Goiás. Centro de Apoio Operacional da Infância, Juventude e Educação. Recomendação de 25 de setembro de 2009. Disponível em $<$ http://www.mp.go.gov.br/portalweb/hp/8/docs/recomendacao_pnbe_-_mec corrigida.pdf > Acesso em: 10 out. 2012.

PAIVA, Aparecida et al. Literatura na infância: imagens e palavras. Acervos do PNBE 2008 para a Educação Infantil. Brasília: MEC, 2008. 
PAIVA, Aparecida. Selecionar é preciso, avaliar é fundamental: acervos de literatura para jovens leitores. Educação, Porto Alegre, v. 35, n. 3, p. 301-307, set./dez. 2012.

PAIVA, Fabrícia V. A literatura infanto-juvenil na formação social do leitor: a voz do especialista e a vez do professor nos discursos do PNBE 2005. Rio de Janeiro: UFRJ, FE, 2008. Dissertação (Mestrado).

PELTASON, Timothy. Seeing things as they are. Literary Imagination, v. 9, n. 2, 2007, p. 177-194. Doi: 10.1093/litimag/immo24 Acesso em 20 mar. 2011.

RAMOS, Paulo. MEC defende distribuição de obras de Will Eisner a escolas. Blog dos Quadrinhos. 23 jun. 2009. Disponível em: <http://blogdosquadrinhos.blog.uol.com. br> Acesso em: 10 out. 2012.

RIBEIRO, Veridiana. Diretor de escola recolhe livros com palavrões de biblioteca em União da Vitória (PR). Folha de São Paulo. 18 de jun. 2009. Disponível em <http://www1. folha.uol.com.br/folha/educacao/ult3054583250.shtml> Acesso em: 10 out. 2012.

SILVA, Bruna L. M. da. Programa Nacional Biblioteca da Escola - edição 2006: a chegada dos acervos na Rede Municipal de Ensino de Belo Horizonte e a leitura de obras por jovens leitores. Belo Horizonte: UFMG, FE, 2009. Dissertação (Mestrado).

SILVEIRA, Rosa M. H. e BONIN, Iara T. A temática indígena em livros selecionados pelo PNBE: análises e reflexões. Educação, Porto Alegre, v. 35, n. 3, p. 329-339, UFN UFMG. Faculdade de Educação. Centro de Alfabetização, Leitura e Escrita (Ceale). Programa Nacional Biblioteca da Escola: análise descritiva e crítica de uma política de formação de leitores. Disponível em: < http://portal.mec.gov.br/dmdocuments/ pnbe.pdf> Acesso em: 11 jan. 2012a.

UFMG. Faculdade de Educação. Centro de Alfabetização, Leitura e Escrita (Ceale). Banco de dados do CEALE. 2012b.

VIEIRA, William. Caçada ao racismo. Carta Capital. 21 set. 2012. Disponível em: <http:// www.cartacapital.com.br/sociedade/cacada-ao-racismo-2 >Acesso em 10 out. 2012.

ZILBERMAN, Regina. A literatura infantil na escola. São Paulo: Global, 2003. 